\title{
EDITORIAL
}

\section{Showcasing the breadth of endocrinology}

\section{We look for an eye-catching image that represents} an aspect of endocrinology
Every year, Nature Reviews Endocrinology runs a competition to find an image to feature on our front covers for the next year. We have received some stunning images over the years, and this year has been no exception. We look for an eye-catching image that represents an aspect of endocrinology. This year, we received images from the breadth of endocrinology, including diabetes mellitus, obesity, bone, pituitary gland and menopause.

The image on our front cover features the pancreatic microenvironment in a patient with type 2 diabetes mellitus. Deep-tissue confocal microscopy with optical clearing was used, which highlights the infiltration of adipose tissue in the pancreas. The image is particularly relevant to endocrinology now, as researchers around the world attempt to understand and address the epidemics of obesity and type 2 diabetes mellitus.

Sandra Orsulic submitted an image that shows the vascular and connective tissue in an ovary during menopause (FIG. 1a). The factors that contribute to the development of ovarian cancer in women during and after menopause are unclear. After menopause, the number of ovarian follicles is reduced, and the remaining ovarian tissue is remodelled to fibrotic scar tissue. "We postulate that the collagen-rich microenvironment of the postmenopausal ovary provides fertile soil for the seeding of neoplastic tubal cells," explains Orsulic. Orsulic and her colleagues hope that their work will improve the understanding of ovarian cancer pathogenesis, which could help researchers to develop prevention and detection strategies. Orsulic stresses that these strategies are urgently needed in clinical practice.

Another of the images that we considered for the front cover was a histological section from a patient with osteomalacia (FIG. 1b), submitted by Daniel Chappard.
The image illustrates excess uncalcified osteoid tissue (red) surrounding the calcified bone (green). Some mineralization defects are also visible in the centre of the trabecula, in red. Chappard explains that this patient developed osteomalacia as a result of vitamin $\mathrm{D}$ deficiency.

Hosung Bae submitted an image of the inguinal white adipose tissue of an 8-week-old male C57BL/6 mouse (FIG. 1 C). Several papers have suggested that CD36, also known as fatty acid translocase, mediates the transport and accumulation of lipids. Bae explains that this image is one of only a few that shows immunofluorescent expression of CD36 in vivo (green). Importantly, expression was seen not just in adipocytes but also along the vasculature. Bae and co-workers are currently experimenting with various ways to regulate the activity of CD36.

The image submitted by Patrice Mollard addresses the question of how pituitary somatotrophs build up pulses of growth hormone (FIG $1 \mathrm{~d}$ ). "The somatotrophs are organized as a $3 \mathrm{D}$ cell network (mouse cells expressing enhanced green fluorescent protein eGFP), which is in close proximity with pituitary fenetrated capillaries (filled with red fluorescent gelatin)," explains Mollard. The capillaries dynamically deliver hypothalamic secretagogues and oxygen to the cell network, but also capture and integrate growth hormone secreted from the cell network as highly ordered pulses of growth hormone.

We would like to thank all of the people who submitted their beautiful images to our competition and apologize to those we couldn't feature here. It was very difficult to choose between the images, but we look forward to seeing the entries for next cover competition!
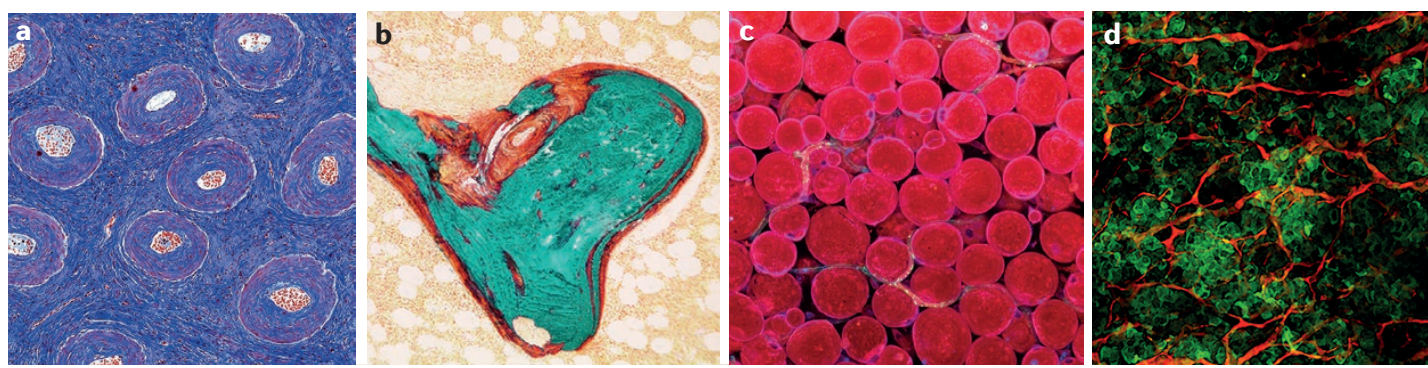

Figure 1 | A selection of entries in our cover competition. a | Ovarian vascular and connective tissue. $\mathbf{b} \mid$ Osteomalacia. c|Adipose tissue showing expression of CD36. d | 3D cell network in the pituitary gland. 